\title{
The role of peers in estimating tenure-performance profiles: evidence from personnel data
}

Citation for published version (APA):

de Grip, A., Sauermann, J., \& Sieben, I. J. P. (2011). The role of peers in estimating tenure-performance profiles: evidence from personnel data. Researchcentrum voor Onderwijs en Arbeidsmarkt, Faculteit der Economische Wetenschappen. ROA Research Memoranda No. 14 https://doi.org/10.26481/umaror.2011014

Document status and date:

Published: 01/01/2011

DOI:

10.26481/umaror.2011014

Document Version:

Publisher's PDF, also known as Version of record

\section{Please check the document version of this publication:}

- A submitted manuscript is the version of the article upon submission and before peer-review. There can be important differences between the submitted version and the official published version of record.

People interested in the research are advised to contact the author for the final version of the publication, or visit the DOI to the publisher's website.

- The final author version and the galley proof are versions of the publication after peer review.

- The final published version features the final layout of the paper including the volume, issue and page numbers.

Link to publication

\footnotetext{
General rights Owners
rights.

- You may freely distribute the URL identifying the publication in the public portal. please follow below link for the End User Agreement:

www.umlib.nl/taverne-license

Take down policy

If you believe that this document breaches copyright please contact us at:

repository@maastrichtuniversity.nl

providing details and we will investigate your claim.
}

Copyright and moral rights for the publications made accessible in the public portal are retained by the authors and/or other copyright owners and it is a condition of accessing publications that users recognise and abide by the legal requirements associated with these

- Users may download and print one copy of any publication from the public portal for the purpose of private study or research.

- You may not further distribute the material or use it for any profit-making activity or commercial gain

If the publication is distributed under the terms of Article $25 \mathrm{fa}$ of the Dutch Copyright Act, indicated by the "Taverne" license above, 
1) Maastricht University

Research Centre for Education and the Labour Market | ROA

The role of peers in estimating tenureperformance profiles: Evidence from personnel data

Andries de Grip

Jan Sauermann

Inge Sieben

\section{ROA Research Memorandum}

ROA-RM-2011/14

Research Centre for Education and the Labour Market Maastricht University

P.O. Box 616,6200 MD Maastricht, The Netherlands

$\mathrm{T}+31433883647 \mathrm{~F}+31433884914$

secretary-roa-sbe@maastrichtuniversity.n www.roa.nl 


\title{
The role of peers in estimating tenure- performance profiles: Evidence from personnel data
}

\author{
Andries de Grip \\ Jan Sauermann \\ Inge Sieben \\ ROA-RM-2011/14* \\ November 2011
}

Research Centre for Education and the Labour Market

Maastricht University

P.O. Box 616, 6200 MD Maastricht, The Netherlands

$\mathrm{T}+31433883647 \mathrm{~F}+31433884914$

secretary-roa-sbe@maastrichtuniversity.nl

www.roa.nl

\footnotetext{
* The ROA Research Memorandum Series was created in order to make research results available for discussion, before those results are submitted for publication in journals.
} 


\section{Abstract \\ The role of peers in estimating tenure-performance profiles: Evidence from personnel data**}

In this paper, we estimate tenure-performance profiles using unique panel data that contain detailed information on individual workers'performance. We find that 10 per cent increase in tenure leads to an increase in performance of 5.5 per cent of a standard deviation. This translates to an average performance increase of about 75 per cent within the first year of the employment relationship. Furthermore, we show that there are peer effects in learning on-the-job: Workers placed in teams with more experienced and thus more productive peers perform significantly better than those placed in teams with less experienced peers. An increase in the average team tenure by one standard deviation leads to an increase of 11 to 14 per cent of a standard deviation in performance.

JEL classification: J24, D24, L89

Keywords: tenure-performance profiles, experience, learning-on-the-job, peer effects, productivity, call centres

Andries de Grip

ROA

P.O. Box 616

NL-6200 MD Maastricht

The Netherlands

a.degrip@maastrichtuniversity.nl

and Institute for the Study of Labor (IZA),

Bonn

Inge Sieben

Tilburg University

Department of Sociology

P.O. Box 90153

NL-5000 LE Tilburg

The Netherlands

i.j.p.sieben@uvt.nl
Jan Sauermann

ROA

P.O. Box 616

NL-6200 MD Maastricht

The Netherlands

j.sauermann@maastrichtuniversity.nl

and Institute for the Study of Labor (IZA),

Bonn

\footnotetext{
** The authors would like to thank Eric Bonsang, Ben Kriechel, Olivier Marie, seminar participants at Maastricht University, SOLE (Cambridge, MA), EALE (Tallin) and EEA (Barcelona) for helpful comments. This paper has been screened to ensure no confidential information is revealed.
} 


\section{Introduction}

Besides investments in formal training, tenure has shown to be an important determinant for workers' productivity as indicated by their wages (Mincer, 1958). The main argument for wages increasing with tenure is that workers accumulate human capital which is then rewarded by higher wages. Previous literature on tenure-performance profiles shows that there are indeed substantial gains from experience (Bishop, 1989; Kostiuk and Follmann, 1989; Shaw and Lazear, 2008). It is, however, not only likely that workers learn from practising their tasks, but also from observing or imitating peers at work (Barron et al. 1989). When there are possibilities for learning from others, a worker's output may not only increase with tenure, but also through being exposed to more experienced peers.

In this paper, we estimate tenure-performance profiles for the first year in a job using individual performance information of call agents taken from personnel records of a large call centre, which is part of a multinational telephone company in the Netherlands (see De Grip and Sauermann, 2012). We find that there is a large marginal return to tenure in the first months of working for the call centre which decreases substantially after gaining some experience. This profile closely follows a logarithmic specification. A 10 per cent increase in tenure is related to an increase of 5.46 per cent of one standard deviation in performance. For the first 12 months of working in the department analysed, this amounts to an increase of about 75 per cent in performance. We interpret this increase in performance as the result of learning on-the-job. When we relate our findings to data on the number of hours the firm invests in formal training, we find that the number of hours invested in learning on-the-job is almost twice as large as the investments in formal training programmes for newly hired agents.

Furthermore, we analyse peer effects in learning, and estimate whether the shape of the estimated tenure-performance profile depends on the composition of teams. Our findings show that there are peer effects when agents are working with more experienced peers in their team. If average peer tenure increases by one standard deviation, agents' 
performance increases by 11 to 14 per cent of a standard deviation in performance. Our results suggest that in the workplace we analyse learning-by-doing is more important for learning than learning from others. We show that our results are robust against alternative hypotheses, especially against the hypothesis of selective labour turnover. Furthermore, we show that the number of hours worked affects the shape of the estimated tenureperformance profile; a result which may be explained by ability-sorting. In addition, we test whether the increase in performance, which is measured as the average length of calls, comes at the cost of decreases in quality. Although we do not find a negative effect on direct measures of customer satisfaction, we do find a negative relationship between tenure and the number of customers calling back within a few days after the call. Overall, it seems that the increase in quantitative performance outweighs the decrease in the number of customers calling back.

This study contributes to the literature on estimating the effects of experience on workers' productivity. These studies originate from the literature on estimating the effects of tenure on wages (see Altonji and Williams (2005) for an overview). One of the main arguments for upward sloping tenure-wage profiles is that it reflects an increasing stock of human capital which is rewarded by higher wages (Mincer, 1958). It has been shown, however, that estimating tenure-wage profiles is problematic for a variety of reasons, such as controlling for trends in wages, sample selection and sample attrition (Altonji and Williams, 2005). Furthermore, using wages instead of output may underestimate the actual returns on learning-by-doing (Shaw and Lazear, 2008). One way to overcome these issues is to use performance data from personnel records. Data taken from personnel records often contain direct measures of performance and can deal with sample selection and attrition since the full sample is observed. Carroll et al. (1986) and Kostiuk and Follmann (1989) use the number of contracts produced by Navy recruiters as a proxy for performance and find that individual performance substantially increases in the first months of their employment. Shaw and Lazear (2008) use information about performance 
of windshield installers in a US-American firm to estimate tenure-performance profiles, and find that output increases by 53 per cent within the first eight months on the job! 1

In contrast to these previous studies on the estimation of learning curves, we also analyse whether working with experienced peers affects learning. Barron et al. (1989) provide evidence that workers spend a substantial part of learning investments on watching other workers performing their tasks. Their findings suggest that the working environment is important for the learning process in the workplace. Destré et al. (2008) estimate the relative importance of self-learning and learning from others using establishment data from France. They show that workers can learn about 10 per cent of their own stock of human capital from co-workers. Battu et al. (2003) and Moretti (2004) find evidence for positive human capital spill-overs within firms and across firms, respectively. Several studies using information from personnel records find positive externalities either through social ties (Bandiera et al., 2010) or simply through spatial proximity (Sacerdote, 2001; Zimmerman, 2003; Falk and Ichino, 2006; Mas and Moretti, 2009). In contrast to these studies, Guryan et al. (2009) do not find significant peer effects on workers' performance, suggesting that peer effects might be related to specific industries, occupational groups or tasks.

The data used in this study have several key features that allow us to estimate unbiased tenure-performance profiles and the effect of peers on the shape of this profile. First, we observe all agents working in the call centre over a period of 30 months. All agents must perform the same tasks irrespective of their tenure, and face the same incentives set by the call centre's management. Given the relatively high turnover of agents, this setting provides substantial variation in tenure and a large number of newly hired agents, which allows us to estimate tenure-performance profiles across tenure in the first year in the job. Furthermore, we are able to control for endogenous selection of call agents out of the call centre.

\footnotetext{
${ }^{1}$ There is a related literature analysing learning at the firm level (Benkard, 2000) which distinguishes between experience effects and spill-over effects in learning within firms (Thornton and Thompson, 2001).
} 
Second, our data provide very detailed information about individual performance, observable for each week an agent works. Following other studies using similar data on call centre agents (e.g. Castilla 2005; Liu and Batt 2007; De Grip and Sauermann 2012), we use a measure of performance that is based on the average handling time of calls. This measure has the advantage of being objective, as it is automatically generated and stored and thus not subject to potentially biased evaluations by supervisors (Flabbi and Ichino, 2001). Furthermore, it is preferable to wage data because it directly measures performance, while wages are often fixed under hourly pay (Shaw and Lazear, 2008). Besides performance information, the data also contain information on investments in formal training programs. As there are no vocational training programmes for call agents, we can calculate workers' total stock of formal training.

Third, the data allow us to analyse peer effects between agents who work in the same team. Despite a growing interest in the effects of social interaction in the workplace, peer effects on worker productivity are difficult to identify (Manski, 1993). A few studies use truly randomised variation in the assignment of workers to peers to identify peer effects (e.g. De Grip and Sauermann, 2012). A second strand of studies use quasi-exogenous variation of workers in teams where one would not expect endogenous sorting (e.g. Mas and Moretti, 2009). In this study, agents who belong to the same team are located next to each other on the work floor. We exploit the quasi-random variation in assignment to shifts as well as to teams to identify peer effects on workers' individual performance.

The paper is structured as follows. In Section 2, we describe the setting of this study and present arguments for both learning-by-doing and learning from others. In Section 3 , we discuss our empirical model and present the estimates of the tenure-performance profile of call agents and the effects of peers on workers' tenure-performance profile. Section 4 shows some robustness analyses and Section 5 summarises and concludes. 


\section{The firm}

\subsection{Information on the workplace}

To estimate tenure-performance profiles and the impact of peers on the shape of these profiles, we use panel data of call agents in a call centre. The call centre belongs to a multinational telecommunications company in the Netherlands, and is segmented in five departments which are distinguished by the type of customer. In order to analyse a homogenous production process, we focus our analysis on the largest department which handles inbound calls of private customers with fixed contracts. In the course of the observation period, 440 agents worked for this department. All agents have the same task of handling customer calls in case of questions, complaints or problems. Other interactions with customers such as written correspondence are dealt with by other backoffice employees.

The data contain objective performance information for each call agent in each week that the agent is working. The performance measure $y_{i t}$ is based on the average handling time $a h t_{i t}$ of agent $i$ in calendar week $t$. It measures the average time an agent spent talking to customers and logging the information about the call in the customer database. This measure has the advantage in that it is automatically generated and is not affected by potentially subjective performance evaluations by supervisors. In recent studies using data on call agents, similar outcomes are used to proxy an agent's productivity (e.g. Castilla, 2005; Liu and Batt, 2007; De Grip and Sauermann, 2012). Furthermore, it is used by call centre management as the key performance indicator for monitoring performance of agents in the call centre. The main objective of management is to decrease average handling time without decreasing the quality provided by the agents. We therefore interpret shorter calls as beneficial to the firm, and define productivity as $y_{i t}=\frac{100}{a h t_{i t}}$. Decreasing average handling time $a h t_{i t}$ is thus interpreted as an increase in performance $y_{i t}{ }^{2}$

\footnotetext{
${ }^{2}$ We deal with potential quality-quantity trade-offs in Section 4.3 .
} 
Agents are organised into 16 teams, each of which is led by a team leader who is responsible for monitoring and coaching agents. In general, all teams provide all services, that is, there is no specialisation of teams in handling certain types of calls or serving certain types of customers. All teams work on the same floor of the building. Work places are organised into work islands, with up to eight agents of a team sitting next to each other. Though there is no team work embedded in the production process, the spatial proximity implies that there is scope for peer effects through learning from peers by exchanging information.

Although agents' performance is continuously measured, agents are paid a flat pay with an adjustment once a year. After a formal evaluation by the team leader after an annual appraisal interview, agents can receive a wage increase of up to eight per cent. There are no other explicit incentives.

\subsection{Sample selection and descriptive statistics}

Our data covers all agents working in the selected department between October 2007 and March 2010. In total, 440 individuals were working for this department for at least one week in this period. To estimate tenure-performance profiles of agents, however, we restrict the sample to all employees with less than one year of tenure. There are several reasons for this restriction. First, focusing on the first year of tenure reduces the likelihood of biased results due to selection because personnel turnover is relatively high in call centres in general (Batt et al., 2006). In this call centre, 49 per cent of all agents observed in our data leave the department within the first year, either to other departments within the call centre or out of the firm. Because this selection is potentially non-random, we focus on the first year of tenure to limit the effect of selection on the estimated tenure-performance profile. The high turnover of call agents also implies that there are less data to estimate tenure-performance profiles beyond one year of tenure 
(Panel (a) of Figure 1), while there are sufficient data for estimating tenure-performance profiles among agents in the first year (Panel (b) of Figure 1) $!^{3}$

Second, human capital theory implies that learning effects are highest in the beginning of an agent's career. Because of faster learning, it is reasonable to expect that workers' performance is more likely to be affected by tenure in this period compared to later periods. This pattern can easily be seen by the solid line depicted in Figure 2 which shows that the average performance $\bar{y}_{i t}$ increases in tenure. After a very steep increase in the beginning, the marginal returns to tenure decrease. This figure shows that there is substantial learning in the agents' task in the first months of the employment relationship, but much less thereafter.

Column (1) of Table 1 shows the descriptive statistics of all agents working in the call centre department we analyse $(N=440)$. Thirty-three per cent of the agents in the sample are men, and their average age is 29 years (Column (1) of Table 1). The average number of working hours is 21.4 hours per week. These figures are comparable to call centres in general which are characterised by a predominantly female workforce with a substantial proportion of part-time workers (Batt et al., 2009).

In Column (2) of Table 1, descriptive statistics of the estimation sample, which comprises all observations with less than one year of tenure, are shown. Compared to the full sample of workers (Column (1)), agents with less than one year of tenure have on average lower performance (0.297 compared to 0.314). Figure 3 shows both the kernel density of performance for all agents (dashed line) and for agents with a maximum of one year of tenure (solid line). It illustrates that there is a substantial shift from the performance of starting agents to the performance of more experienced agents.

To shed more light on non-random selection of agents out of the sample, we focus on agents which we can observe from their first tenure-week (Column (3) of Table 1). Within this sample, we can precisely observe when and which agents leave the sample (see Shaw

\footnotetext{
${ }^{3}$ To reduce the number of outliers, we also drop all observations that have calls shorter than the first per centile or longer than the ninety-ninth per centile. In most cases, these extreme average handling times were caused by a very low number of calls.
} 
and Lazear, 2008). When comparing the observations of agents leaving the sample within the observation period ('leavers', Column (4)) with those staying in the sample during that period ('stayers', Column (5)), we find that stayers are slightly more productive, have more tenure, and work substantially more hours than leavers (Column (6)). Though the group of leavers can comprise positive as well as negative sorting of agents, this result suggests that agents leaving the department are on average a negative selection.

\section{Estimating tenure-performance profiles}

\subsection{Baseline results}

The average tenure-performance profile for agents in their first year of working for the department is shown in Figure 2. The solid line depicts average performance, controlling for general time-trends and fluctuations which are measured by week fixed-effects. The figure shows a steep tenure-performance profile in the first six months of working in the call centre. After this period, performance is still increasing, but at substantially lower rates than in the first six months. This result suggests that there is substantial learning about how to handle customer calls in the first months of the employment relationship but not thereafter.

In order to estimate the agents' tenure-performance profile, we model the effect of tenure $d_{i t}$ on performance $y_{i t}$ as a linear-log function. The linear-log prediction, which is depicted by the dashed line in Figure 2 , provides the best approximation of the nonparametrically estimated tenure-performance profile compared to other functional forms. Our regression model can thus be written as:

$$
y_{i t}=\alpha+\log \left(d_{i t}\right)^{\prime} \beta_{1}+X_{i t}^{\prime} \beta_{2}+\gamma_{t}+u_{i t}
$$

where the unit of observation is agent $i$ in calendar week $t$. The slope of the tenureperformance profile is thus estimated by $\beta_{1}$. The vector $X_{i t}$ indicates whether the agent 
had a previous employment relationship with the same call centre, the number of working hours in week $t$, as well as the agent's gender. Average performance fluctuates substantially around its mean, due to such issues as technical network problems, problems with the internal IT-system, or changes in the composition of types of calls. To control for these aggregate shocks, we add week fixed-effects $\gamma_{t}$ to Equation (1). The effect of tenure on performance can be identified from general time trends because the timing of entry dates varies across all agents. The idiosyncratic error term $u_{i t}$ is clustered to allow for within-agent correlation.

In general, it is possible to estimate Equation (1) including individual fixed-effects (see Shaw and Lazear 2008). Because tenure and time are perfectly collinear, however, the effect of tenure cannot be identified unless making ad-hoc assumptions such as the equality of two specific fixed effects. ${ }^{4}$ Equation (1) is therefore estimated using pooled ordinary least squares.

The main regression results are shown in Table 2, Despite piecewise adding control variables $X_{i t}$ and week fixed-effects to the regression, the estimated effect of tenure on performance $\left(\widehat{\beta}_{1}\right)$ is hardly affected and stays at about 0.045 . Our preferred specification, which is shown in Column (5), includes the full set of covariates. The results show that, over the first year working for the call centre, an increase of 10 per cent in tenure is related to an increase in performance $y_{i t}$ of 0.00442 . Given a standard deviation of performance of 0.081 , this relates to an increase of 5.5 per cent of a standard deviation in performance.

To control for agent-specific characteristics, we included a set of control variables. First, to control for previous employment spells as a call agent, we use a dummy variable Previous Employment which is defined as being one (1) if the agent had a employment relationship with the same call centre before the current employment relationship. Among agents in our estimation sample, 4.5 per cent had previous employment relationships with this call centre (Column (2) of Table 1). Agents who had an employment relationship

\footnotetext{
${ }^{4}$ In order to assess the impact of individual fixed effects on the estimated tenure-performance profile, we also estimated Equation (1) with and without individual fixed effects, both without week fixed effects. The results show that there is no statistical difference between the effect of the tenure variable of the two models. The results are available upon request from the authors.
} 
with the call centre prior to the current employment relationship perform 0.0399 (i.e. 49.3 per cent of one standard deviation in performance $y_{i t}$ ) better than agents without previous employment. This suggests that agents who previously worked in this centre have accumulated skills which enable them to work at a faster pace, compared to new hires without previous employment in the call centre.

Second, we include the number of weekly working hours in order to control for the amount of time an agent spends on learning-by-doing. Third, we control for an agent's gender. Both variables, however, do not have a significant effect on the shape of the estimated tenure-performance profile.

\subsection{Investments in learning on-the-job}

Our interpretation of the shape of the tenure-performance profile is that increases in performance reflect an agent's stock of skills. The shape can thus be used to estimate the size of the firm's implicit investment in learning on-the-job, $G$. Given supply of experienced workers, the firm could either appoint an experienced agent for a vacant position, or can hire an inexperienced agent with zero tenure to fill the vacancy. The implicit investment comes from the fact that inexperienced agents are learning and thus perform worse than experienced agents in the first months of employment. We therefore assume that an inexperienced agent starts with performance $y_{d=1, i t}$ in the first working week $d=1$ and then follows the tenure-performance profile estimated by Equation (1) until the agent can work at the performance level of an experienced agent in (tenure) week $d=K, y_{d=K, i t}$.

After calculating the difference between the two agents $y_{d=K}-y_{k} \forall k=1, \ldots, K-1$, we transform this number to the difference in average handling time, and multiply it by 
the average number of calls an experienced agent handles in one week, $c_{k, i t}$. We interpret the difference, $G$,

$$
G=\sum_{k=1}^{K}\left(\frac{100}{y_{d=K}-y_{k}}\right) \cdot c_{k, i t}
$$

as the learning investment of untrained workers. When estimating $G$ for an average agent, we find that 161.7 hours of learning are required before a new hire has the same productivity as an experience agent. All other things equal, the firm has to invest this amount of 'learning on-the-job', minus the wage difference between the two agents. In fact, these opportunity costs of hiring an inexperienced worker are about twice as high as the call centre's investment in hours of formal training, which accumulates to 84.1 hours of formal training programs in the first year.

\subsection{Team composition and tenure-performance profiles}

The actual task of agents, handling customer calls, is an individual production process $5^{5}$ Despite the fact that there is no joint team work, peer effects are plausible in our context, because agents do the same task regardless of their tenure, and teams are located next to each other at the workplace. Peer effects are more likely between agents of the same team, compared to peer effects between agents of different teams, because agents of one team sit next to each other, while agents of other teams have a larger spatial distance at the work floor. Moreover, agents who belong to the same team may exchange workrelated information and knowledge during team meetings ${ }^{6}$ In addition, agents with higher tenure probably have more skills to handle calls, retrieve information from the customer

\footnotetext{
${ }^{5}$ This does not preclude that there are externalities from an individual worker's production to the worker's peers. In the present setting, providing low quality can lead to customers calling back. These repeat calls may have to be treated more carefully. We argue, however, that this does not affect our estimate. First, agents are monitored thoroughly by their team leaders who can listen in on calls. Second, since calls are randomly assigned to agents in the call centre, all agents have the same probability of receiving calls from customers calling back.

${ }^{6}$ This argument does not preclude that peer effects also arise between agents of different teams. If there are also between-team peer effects, our estimated within-team peer effect can be interpreted as a lower bound of the true peer effect.
} 
to deal with the customer's problem efficiently, and to use the computer software system, compared to new hires. This argument is supported by the outcomes of the analysis in Section 3.1, which shows a steep tenure-performance profile over the first year of tenure.

We use three different variables to capture the effect of peers on a worker's own performance. The first two variables used to proxy peer effects are average performance of peers in an agent's team, and the peers' average tenure. We use both variables lagged by one period, i.e., one working week. The reasoning for using lagged values instead of contemporaneous values is twofold. First, one argument for peer effects is that workers learn from their peers. It is more likely that peer performance and peer tenure do not have an immediate effect but should rather pay off after having learned from peers. Second, using lagged peer performance avoids the problem of simultaneous determination of both outcome $y_{i t}$ (agent's performance) and peers' performance, for instance due to common shocks to performance.

The third variable used to proxy peer effects is the average peer experience, cumulated over an agent's tenure, and normalised by the agent's tenure. The reasoning for this variable is that we want to measure the cumulative effect of being exposed to more experienced agents; the variable therefore measures the cumulative exposure to tenure. To be able to compare the effects of the three peer variables, all are standardised with a zero mean and a standard deviation of one. Descriptive statistics of the peer variables are shown in Table 3 .

The effect of the peer variables on workers' performance is estimated in three separate regressions by augmenting Equation (1) by the variable $d_{i t}$ which captures information on peers:

$$
y_{i t}=\alpha+\log \left(d_{i t}\right)^{\prime} \beta_{1}+X_{i t}^{\prime} \beta_{2}+\gamma_{t}+d_{i t}^{\prime} \theta+u_{i t}
$$

We estimate the effect of the three distinct definitions of the variable $d_{i t}$ separately. Each of the peer variables is calculated as the average for agent $i$ in the previous week $t-1$. 
All peer variables take into account that an agent is exposed to another agent who works the same hours because the peer variables are weighted by the number of joint working hours of agent $i$ with the worker's peers' working hours in the same week.

Because information on when an agent enters and leaves the call centre is available for a shorter time period only, the number of observations drops from 7,623 (356 agents) to 3,430 (237 agents). For this reason, Column (1) of Table 4 first shows the estimation results of Equation (1) with the sample used to estimate peer effects. The estimated effect of log-tenure on the measure of performance, $y_{i t}(0.048)$ does not significantly differ from the previous estimate (Column (5) of Table 2). The other columns of Table 4 shows the estimation results of Equation 3. Columns (2) and (3) show the effect of peer performance and peer tenure on a worker's own performance, whereas Column (4) shows the effect of cumulated peer experience. All three variables significantly affect workers' own performance, with the main effect of tenure not significantly changing from the baseline model (Column (1)). When including the average performance of agents who were working with the agent in the previous week (Average team performance $t-1$ ), log-tenure has an effect of 0.049 (Column (2)). An increase of one standard deviation in average team performance in the previous week $(t-1)$, is related to an increase in workers' own performance of 0.0097 . This is the equivalent to 11 per cent of one standard deviation in the outcome variable $y_{i t}$. The use of peer performance may, however, raise concerns, because it may be driven by simultaneous determination of both workers' own performance $y_{i t}$ and peer performance $d_{i t}$. We therefore estimate Equation (3) with lagged average team tenure as the proxy for peer effects (Column (3) of Table 4), and find a significant coefficient of 0.109 . This translates to an effect of 13.5 per cent of a standard deviation in $y_{i t}$ when increasing average tenure of a worker's team mates by one standard deviation. As a third proxy for peer effects, we use cumulative average team tenure, divided by the number of weeks an agent has worked in the call centre. The estimated coefficient is significant, and relates to an increase in $y_{i t}$ of 10.9 per cent of a standard deviation in performance when the cumulative team mates' tenure increases by one standard deviation. 
Independent of the specification of the peer variable, the results presented in Table 4 show that having worked with better performing or more experienced peers improves a worker's performance. One standard deviation increase in the average performance or the average tenure of a worker's peers leads to an increase in the agent's performance between 11 and 13.5 per cent of a standard deviation. These results show that it may be beneficial to the firm to place new agents in more experienced teams. When calculating $G$ as in Equation (2) based on the sample used in Table 4 , the learning investment accumulates to 164 hours over the first year of tenure. When including average peer tenure as an additional control variable, this number reduces to 157 hours. If we interpret the difference between the two estimates as the size of overestimation when not correcting for peer effects, the investments $G$ which are due to learning-by-doing are overestimated by 4.3 per cent.

\section{Robustness analyses}

\subsection{Turnover and selection of workers}

Call centres face relatively high turnover of workers compared to other sectors of industries (Batt et al., 2006). If turnover is related to individual performance or to unobserved factors that affect both tenure and performance of the individual worker, the shape of the estimated tenure-performance profile is likely to be affected by workers who quit the firm. Therefore, the observed increase in performance by tenure is partly the result of an improved match quality instead of learning on-the-job.

The sample used in this study allows us to compare different types of agents. We can distinguish between agents leaving the department analysed in this study (leavers) and agents who are not leaving (stayers). $]^{7}$ However, since we do not observe agents who left the department before our observation period started, this analysis is likely to be affected

\footnotetext{
${ }^{7}$ We do not have information on the exact date when agents leave the department. We define agents as leavers when they have not worked in the department for 20 or more weeks in a row.
} 
by left-censoring (Shaw and Lazear 2008). We therefore limit the sample to new hires, i.e. agents that we observe from their first working week.

Column (1) of Table 5 shows the results when estimating Equation (1) for new hires only. This sample contains 303 agents, of which 96 are stayers; the remaining 207 agents leave within the observation period. The estimated coefficient for $\log$ (tenure) is very similar to the baseline estimates (Column (5) of Table 2). An increase of tenure by 10 per cent leads to an increase of of 5.5 per cent of a standard deviation of performance (estimated coefficient of 0.0444 ). The estimated effect of $\log$ (tenure) on performance for stayers (0.0516) corresponds to an increase in performance of 6.4 per cent of one standard deviation when tenure increases by 10 per cent. For agents leaving the department, however, the corresponding effect is only 4.8 per cent (0.0385), which is significantly lower than the estimated performance increase for agents who remain employed in the call centre.

These estimation results have two implications. First, the data shows that a substantial share of agents who are observed from their first working week leave the department within our observation period (68 per cent). Second, these agents have significantly lower tenure-performance profiles. This endogenous sorting of agents can be interpreted as a positive selection of agents who stay employed in the department, while the leaving agents comprise a negative selection of workers 8

\subsection{Assignment to teams and shifts}

To identify the causal peer effect on workers' performance development, either truly random assignment by means of experiments (e.g. De Grip and Sauermann, 2012) or quasirandom assignment to groups (e.g. Mas and Moretti, 2009) is required. In this study, the effect of an agent's peers on own performance is identified by quasi-random changes in

\footnotetext{
${ }^{8}$ The difference between the estimated tenure-performance profile of leavers and stayers can be affected by the tenure-segment one observes. When estimating the same regressions for agents with a maximum tenure of 3 months, the estimated tenure-performance profiles are not significantly different from one another. When increasing the tenure-segment, this difference becomes significant.
} 
team composition. Although each agent is assigned to one team supervised by one team leader, there are week-to-week differences in whether an agent is working at all, and in the number of hours an agent is working. Therefore, the agent's composition of team mates differs from week to week.

In order to support the hypothesis of random assignment of agents to teams, we test whether the assignment to teams is selective with respect to ability. We therefore regress a measure of individual ability on the average ability of the team. We generate a measure of ability by using the estimated individual fixed-effects from a regression of performance $y_{i t}$ on a full set of tenure and individual fixed-effects (cf. Mas and Moretti, 2009).

$$
y_{i t}=\eta_{i}+\gamma_{d}+\varepsilon_{i t}
$$

This measure of ability, $\hat{\eta}_{i}$, is then regressed on the average ability of the other workers in the team (Sacerdote 2001). Because we are interested in the team coaches' influence on the selection of new agents, we run this test for agents switching to new team coaches. The explanatory variable, average peer ability $\bar{y}_{i j}$, is thus taken from the agents in the team $j$ to which an agents is switching. Table 6 shows the estimation results of individual ability on average ability in the destination team using agent-week observations after an agent switched to a new team. The results show that average team ability does not have a significant effect on individual ability. This allows us to conclude that there is no ability-based selection for agents when switching team leaders.$^{9}$

Further, it is rather difficult for agents to select themselves into the same hours as particular peers. Agents must be available for scheduling during the opening hours of the call centre, and must state their preferences for particular hours four weeks prior. Based on both their preferences and the expected demand by customers, managers assign agents to particular hours. As a result, both the composition of agents at each point in time and weekly team composition changes frequently. As the scheduling is done for the

\footnotetext{
${ }^{9}$ New agents are recruited by a temporary help agency that selects potential agents who fulfill the job description. The team leader usually does not have any influence on the selection of newly recruited agents and their placement into teams.
} 
whole department and not for individual teams, it is unlikely that there is any strategic planning within teams. Therefore, there is no reason to expect that spurious correlation drives our estimation results of the peer effects.

\subsection{Substitution between quality and quantity of calls}

The performance variable used in this study, average handling time, is a measure of quantitative performance. Following De Grip and Sauermann (2012), we use additional information to estimate the effect on quality of calls. We employ two types of measures to capture quality of agents' calls. The first measure is based on the share of repeat calls. The share of repeat calls is defined as the share of customers to whom an agent spoke who called the call centre again within seven days. This measure is used by management to evaluate the quality of calls, as customers may call again, potentially because the problem is not solved. Low values of repeat calls $\left(r c_{i t}\right)$ are interpreted as high performance. We

therefore define call quality as $y_{i t}^{q}=\frac{1}{r c_{i t} * 10}$, with an average of 0.507 (see Table 3). Figure 4 shows the corresponding non-parametrically estimated tenure-performance profile for this measure of call quality. Call quality appears to decrease in the first 3 months and to flatten thereafter. The estimation results show that with increasing tenure, call quality significantly decreases (-0.0193; Table 7, Column (1)). An increase in tenure by 10 per cent is thus related to a decrease of call quality by 1.1 per cent of one standard deviation in the quality measure. This suggests that despite the fact that quantity is improving substantially over the course of the first months, this partly comes at the cost of lower call quality.

Having information on both average handling time and call quality also allows us to create a composite measure of productivity that contains both dimensions. We thus define $y_{i t}^{\prime}$ as $y_{i t}^{\prime}=y_{i t} *\left(1-r c_{i t}\right)$. For this measure, larger shares of repeat calls $r c_{i t}$ are interpreted as a penalty in performance, since each additional percentage point in the share of repeat calls (lower quality) relates to a lower composite productivity $y_{i t}^{\prime}$. The results, shown in Column (2) of Table 7, indicate that there is a positive effect of tenure 
on the overall measure. The estimated coefficient of 0.0332 is significantly different from zero. A 10 per cent increase in tenure thus leads to an increase in overall productivity of 4.5 per cent of a standard deviation. This suggests that the positive quantity effect outweighs the negative quality effect.

Second, we use information from a customer satisfaction survey as an alternative measure of call quality. This survey is conducted monthly in order to monitor the quality provided by the departments on an aggregate level. Among all incoming calls, customers are selected and called for a short survey. Though there are only about 200 calls evaluated in this way each month, the sample consists of a randomly chosen subset of calls. The survey contains three outcomes related to the agent's quality. Customers were asked to grade the 'knowledge of agent' (Grade 1), whether the 'agent understood question' (Grade 2 ), and whether the agent had a 'solution to the problem' (Grade 3) on a scale from 1 (very bad) to 10 (very good).

Columns (3) through (5) of Table 7 show that, controlling for an agent's previous employment, the number of working hours, the gender, and week fixed-effects, there is no significant relationship between agent's tenure and service quality. Neither the knowledge of the agent, nor whether the agent understood the question or had a solution to the customer's problem appears to be related to tenure.

Overall, these results suggest that the more efficient calls of agents with longer tenure come at the costs of a lower call quality as proxied by repeat calls. Overall, however, our results suggest that performance increases with tenure.

\subsection{Working hours and the shape of tenure-performance profiles}

In the call centre we analyse, there is substantial within- and between-worker heterogeneity in working hours. If learning on-the-job is related to the actual number of hours worked, this heterogeneity may lead to differences in the shape of estimated tenure-performance profiles, depending on the number of working hours. 
In order to assess this possible bias, we generate two alternative measures of tenure: tenure measured in working weeks (as opposed to calendar weeks) and tenure measured in full-time equivalents (fte). Tenure in working weeks is defined as the number of weeks an agent worked in the past apart from holiday weeks and other non-working weeks. The second measure, tenure in fte, is defined as the cumulated number of hours worked, divided by 38. It thus measures the number of fte weeks the agent has been working for the call centre. In order to make the variables comparable to the original tenure variable, both variables are rescaled to years. As it is important to have the full history of the actual working hours of agents for this analysis, we only use new hires.

Table 8 shows the estimation results of regressions of log-performance on the three different tenure definitions. Column (1) shows the estimation results of our baseline with this smaller sample. The baseline estimate using the standard definition of tenure is 0.0444, compared to 0.0442 using the full sample (Column (5) of Table 2). The performance effect of tenure in working weeks in Column (2) is slightly higher (1.58 per cent) than in the analysis with the standard measure of tenure. Since the difference between the two estimates refers to non-working weeks, the result suggests that the tenure-performance profile is actually slightly steeper, than if the non-working weeks are neglected. When using the third definition of tenure, tenure in fte weeks, the effect of tenure appears to be significantly lower than the effect of tenure measured in working weeks. This suggests that agents with more working hours have a tenure-performance profile that is less steep than the tenure-performance profile of workers who work less hours. This result may be explained by sorting high-ability individuals (e.g., students in higher education who work for a shorter time in the call centre) into contracts with shorter working hours.

\section{Conclusion}

In this paper, we analysed tenure-performance profiles of call centre agents, using unique panel data of a multinational telecommunication firm's call centre that contain detailed 
performance information on the individual level. The results show that call agents have a very steep tenure-performance profile in the beginning of their job in the call centre. This increase, however, flattens considerably after about 6 months. The tenure-performance profile can very well be described by a logarithmic function. An increase of tenure by 10 per cent leads to an increase of 5.5 per cent of one standard deviation in performance.

We interpret this increase in performance as learning due to accumulation of human capital. For call agents working for this call centre, the estimated shape of the tenureperformance profile makes sense. The agents' task itself —answering customer callsis repetitive. The highest returns to learning should therefore occur in the beginning of the employment relationship. In our data, agents perform 66.5 per cent better after 8 months which is comparable to related findings from other sectors. After this initial period, the marginal return to tenure decreases. The rather fast learning of agents may be due to the relatively low complexity of the job. In other, more complex jobs, tenureperformance profiles may be less steep. The initially lower pay-off of learning on-the-job can be recouped over longer job spells. These results imply that the firm's investment in learning on-the-job is substantial. The agents' increase in performance translates to a learning investment by the firm of about 162 hours. Over the same period, the firm's investments in formal training are much lower and accumulate to an average of 84 hours.

In addition, we show that workers significantly benefit from working with more experienced peers. We find that an increase in the average team tenure of one standard deviation relates to an increase in performance of 14 per cent of one standard deviation. This shows that it can be beneficial for firms to place new workers in teams with more experienced agents and thereby facilitating knowledge spill-overs between workers even if the workers are not involved in team work. 


\section{References}

Altonji, J. G., And N. Williams (2005): "Do Wages Rise with Job Seniority? A Reassessment," Industrial and Labor Relations Review, 58(3), 370-397.

Bandiera, O., I. Barankay, and I. Rasul (2010): "Social Incentives in the Workplace," Review of Economic Studies, 77(2), 417-459.

Barron, J. M., D. A. Black, and M. A. Loewenstein (1989): "Job Matching and On-the-Job Training," Journal of Labor Economics, 7(1), 1-19.

Batt, R., V. Doellgast, and H. Kwon (2006): "Service Management and Employment Systems in U.S. and Indian Call Centers," in Brookings Trade Forum 2005: Offshoring White-Collar Work-The Issues and Implications, ed. by S. M. Collins, and L. Brainard, pp. 335-372. Brookings Institution Press, Washington, D.C.

Batt, R., D. Holman, and U. Holtgrewe (2009): "The Globalization of Service Work: Comparative Institutional Perspectives on Call Centers," Industrial and Labor Relations Review, 62(4), $453-488$.

Battu, H., C. R. Belfield, and P. J. Sloane (2003): "Human Capital Spillovers within the Workplace: Evidence for Great Britain," Oxford Bulletin of Economics and Statistics, 65(5), 575-594.

Benkard, C. L. (2000): "Learning and Forgetting: The Dynamics of Aircraft Production," American Economic Review, 90(4), 1034-1054.

Bishop, J. H. (1989): "On-The-Job Training of New Hires," CAHRS Working Paper Series 401, Cornell University, School of Industrial and Labor Relations, Center for Advanced Human Resource Studies, Ithaca, NY.

Carroll, V. P., H. L. Lee, and A. G. RaO (1986): "Implications of Salesforce Productivity Heterogeneity and Demotivation: A Navy Recruiter Case Study," Management Science, 32(11), pp. 1371-1388. 
Castilla, E. J. (2005): "Social Networks and Employee Performance in a Call Centre," American Journal of Sociology, 110(5), 1243-1283.

De Grip, A., And J. Sauermann (2012): "The Effects of Training on Own and CoWorker Productivity: Evidence from a Field Experiment," Economic Journal, forthcoming.

Destré, G., L. LÉvy-Garboua, and M. Sollogoub (2008): "Learning from Experience or Learning from Others? Inferring Informal Training from a Human Capital Earnings Function with Matched Employer-Employee Data," Journal of Socio-Economics, 37(3), 919-938.

Falk, A., And A. IChino (2006): "Clean Evidence on Peer Effects," Journal of Labor Economics, 24(1), 39-58.

FlabBi, L., And A. IChino (2001): "Productivity, Seniority and Wages: New Evidence from Personnel Data," Labour Economics, 8(3), 359-387.

Guryan, J., K. Kroft, and M. Notowidigdo (2009): "Peer Effects in the Workplace: Evidence from Random Groupings in Professional Golf Tournaments," American Economic Journal: Applied Economics, 1(4), 34-68.

Kostiuk, P. F., And D. A. Follmann (1989): "Learning Curves, Personal Characteristics, and Job Performance," Journal of Labor Economics, 7(2), pp. 129-146.

Liu, X., And R. Batt (2007): "The Economic Pay-Offs to Informal Training: Evidence from Routine Service Work," Industrial and Labor Relations Review, 61(1), 75-89.

Manski, C. F. (1993): "Identification of Endogenous Social Effects: The Reflection Problem," Review of Economic Studies, 60, 531-542.

Mas, A., And E. Moretti (2009): "Peers at work," American Economic Review, 99(1), $112-145$. 
Mincer, J. (1958): "Investment in Human Capital and Personal Income Distribution," Journal of Political Economy, 66, 281.

Moretti, E. (2004): "Estimating the Social Returns to Higher Education: Evidence from Longitudinal and Repeated Cross-Section Data," Journal of Econometrics, 121, $175-212$.

Sacerdote, B. (2001): "Peer Effects with Random Assignment: Results for Dartmouth Roommates," Quarterly Journal of Economics, 116(2), 681-704.

Shaw, K., And E. P. Lazear (2008): "Tenure and Output," Labour Economics, 15(4), $705-724$.

Thornton, R. A., And P. Thompson (2001): "Learning from Experience and Learning from Others: An Exploration of Learning and Spillovers in Wartime Shipbuilding," American Economic Review, 91(5), 1350-1368.

Zimmerman, D. J. (2003): "Peer Effects in Academic Outcomes: Evidence from a Natural Experiment," Review of Economics and Statistics, 85(1), 9-23. 


\section{A Figures}

Figure 1: Kernel density plot for tenure

(a)

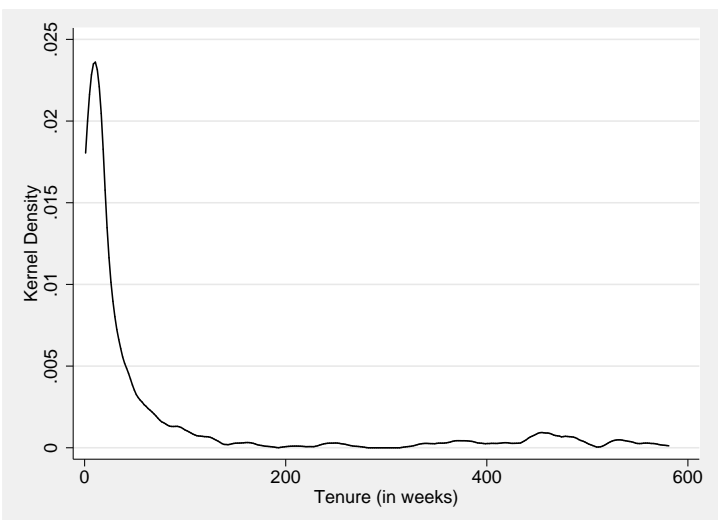

(b)

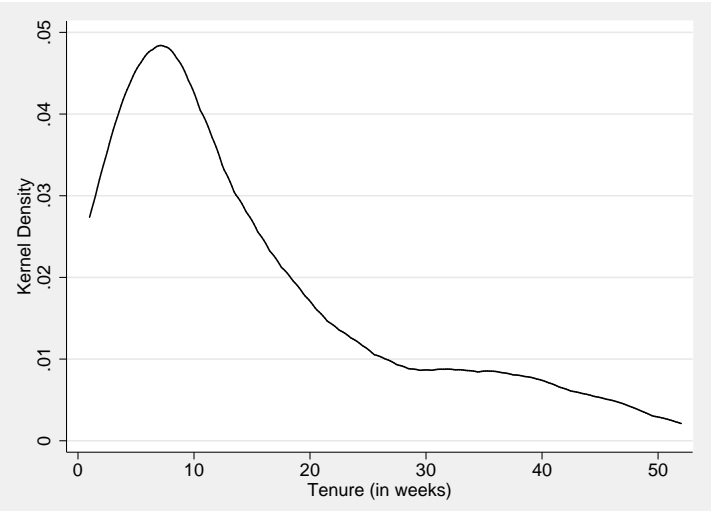

Note: Panel (a) shows the the density plot for all agents, (b) shows the density plot for all agents with a maximum of one year of tenure. Tenure is measured in years and averaged for each agent in the sample.

Figure 2: Non-parametric and logarithmic tenure-performance profiles

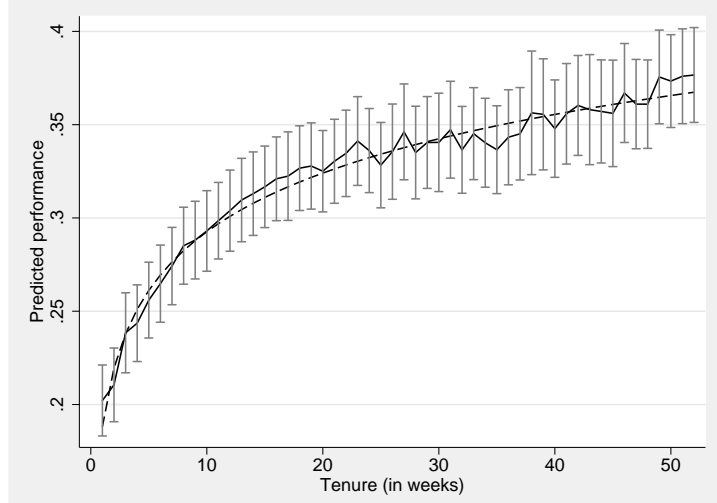

Note: the solid line shows the predicted performance after a regression of performance $y_{i t}$ on tenure fixed-effects and week fixed effects. The capped spikes show the appropriate 95 per cent confidence interval. The dashed line shows the predicted performance after a regression of $y_{i t}$ on $\log ($ tenure). 
Figure 3: Kernel density plot for performance

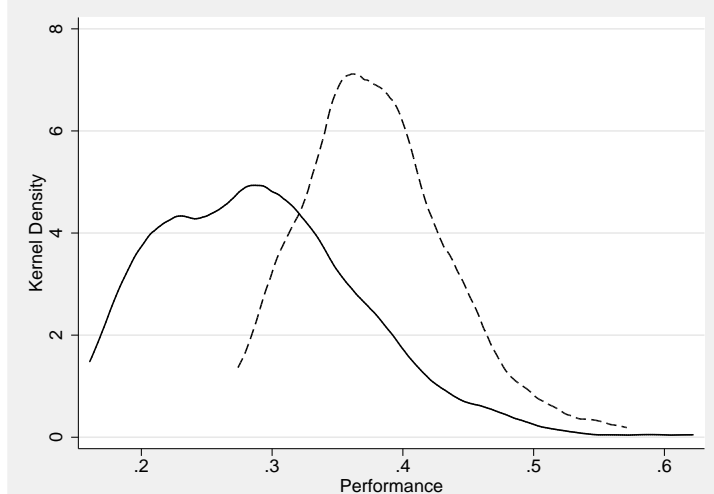

Note: The figure shows the kernel density for performance $y_{i t}$ for all agents with a maximum of one year of tenure (solid line) and for all agents with more than one year of tenure (dashed line). Performance is measured in years and averaged for each agent in the sample

Figure 4: Non-parametric tenure-quality profile

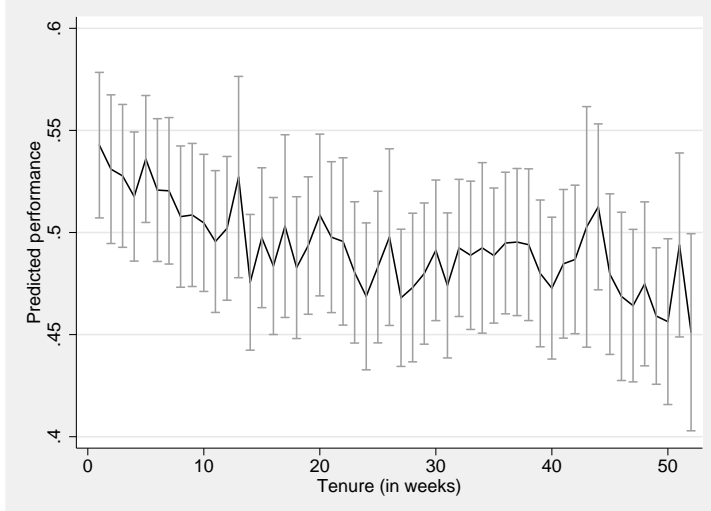

Note: the solid line shows the predicted qualitative performance measure after a regression of performance $y_{i t}^{c}$ on tenure fixed-effects and week fixed effects. The capped spikes show the appropriate 95 per cent confidence interval. 


\section{B Tables}

Table 1: Descriptive statistics (main variables)

\begin{tabular}{|c|c|c|c|c|c|c|}
\hline & (1) & (2) & (3) & (4) & (5) & (6) \\
\hline Tenure restriction & No & \multicolumn{4}{|c|}{ Up to 1 year of tenure } & \\
\hline \multirow[t]{2}{*}{ Sample restriction } & All & All agents & New hires & New hires & New hires & \\
\hline & agents & & All & Leavers & Stayers & Diff. (5)-(4) \\
\hline Performance $\left(y_{i t}\right)$ & $\begin{array}{c}0.314 \\
(0.088)\end{array}$ & $\begin{array}{c}0.297 \\
(0.081)\end{array}$ & $\begin{array}{c}0.283 \\
(0.072)\end{array}$ & $\begin{array}{c}0.279 \\
(0.070)\end{array}$ & $\begin{array}{c}0.292 \\
(0.075)\end{array}$ & $0.016^{*}$ \\
\hline $\begin{array}{l}\text { Tenure } \\
\text { (in years) }\end{array}$ & $\begin{array}{c}1.360 \\
(2.606)\end{array}$ & $\begin{array}{c}0.297 \\
(0.232)\end{array}$ & $\begin{array}{c}0.227 \\
(0.153)\end{array}$ & $\begin{array}{c}0.221 \\
(0.152)\end{array}$ & $\begin{array}{c}0.241 \\
(0.155)\end{array}$ & $0.072^{* *}$ \\
\hline Previous employment & $\begin{array}{c}0.112 \\
(0.316)\end{array}$ & $\begin{array}{c}0.045 \\
(0.207)\end{array}$ & $\begin{array}{c}0.013 \\
(0.114)\end{array}$ & $\begin{array}{c}0.005 \\
(0.070)\end{array}$ & $\begin{array}{c}0.031 \\
(0.175)\end{array}$ & $0.026^{*}$ \\
\hline Working hours & $\begin{array}{l}21.433 \\
(7.489)\end{array}$ & $\begin{array}{l}23.119 \\
(7.121)\end{array}$ & $\begin{array}{l}23.647 \\
(7.298)\end{array}$ & $\begin{array}{l}21.189 \\
(5.549)\end{array}$ & $\begin{array}{l}28.945 \\
(7.812)\end{array}$ & $7.784^{* * *}$ \\
\hline Gender ( $1=$ male $)$ & $\begin{array}{c}0.328 \\
(0.470)\end{array}$ & $\begin{array}{c}0.351 \\
(0.478)\end{array}$ & $\begin{array}{c}0.356 \\
(0.480)\end{array}$ & $\begin{array}{c}0.348 \\
(0.477)\end{array}$ & $\begin{array}{c}0.375 \\
(0.487)\end{array}$ & 0.027 \\
\hline Age & $\begin{array}{c}29.331 \\
(10.105)\end{array}$ & $\begin{array}{l}27.011 \\
(8.192)\end{array}$ & $\begin{array}{l}26.173 \\
(7.846)\end{array}$ & $\begin{array}{l}26.506 \\
(7.496)\end{array}$ & $\begin{array}{l}25.525 \\
(8.492)\end{array}$ & -0.981 \\
\hline Number of agents & 440 & 356 & 303 & 207 & 96 & \\
\hline Number of observations & 15011 & 7623 & 6451 & 4274 & 2177 & \\
\hline
\end{tabular}

${ }^{*} p<0.10,{ }^{* *} p<0.05,{ }^{* * *} p<0.01$. Descriptive statistics are based on the average for each individual agent. Standard deviations in parenthesis. 
Table 2: The Effect of Tenure on Performance

\begin{tabular}{lccccc}
\hline \hline & $(1)$ & $(2)$ & $(3)$ & $(4)$ & $(5)$ \\
\hline $\log$ (tenure) & $.0457^{* * *}$ & $.0448^{* * *}$ & $.0446^{* * *}$ & $.0448^{* * *}$ & $.0442^{* * *}$ \\
Previous employment & $(.0024)$ & $(.0025)$ & $(.0024)$ & $(.0024)$ & $(.0026)$ \\
& & $.0415^{* * *}$ & $.0399^{* * *}$ & $.0411^{* * *}$ & $.0399^{* * *}$ \\
Working hours & & $(.0134)$ & $(.0137)$ & $(.0138)$ & $(.0138)$ \\
& & & -.0003 & -.0003 & .0001 \\
Gender $(1=$ male) & & & $(.0003)$ & $(.0003)$ & $(.0003)$ \\
& & & & .0109 & .0111 \\
Constant & $.3799^{* * *}$ & $.3761^{* * *}$ & $.3830^{* * *}$ & $.3795^{* * *}$ & $.3690^{* * *}$ \\
& $(.0066)$ & $(.0069)$ & $(.0108)$ & $(.0109)$ & $(.0116)$ \\
\hline Week fixed-effects & No & No & No & No & Yes \\
\hline Observations & 7623 & 7623 & 7623 & 7623 & 7623 \\
Number of agents & 356 & 356 & 356 & 356 & 356 \\
$\mathrm{R}^{2}$ & .2124 & .2224 & .2234 & .2261 & .2918 \\
\hline \hline
\end{tabular}

$* p<\overline{\overline{0.10,{ }^{* *} p<0.05,{ }^{* * *} p<0.01 \text {. Dependent variable: } y_{i t} \text {. All regressions are estimated }}}$ using observations with a maximum of one year of tenure. Standard errors are clustered at the agent level.

Table 3: Descriptive statistics (other variables)

\begin{tabular}{lcccc}
\hline \hline & $(1)$ & $(2)$ & $(3)$ & $(4)$ \\
\hline \hline Average team performance $t-1$ & mean & SD & Observations & Agents \\
Average team tenure $t-1$ & -0.207 & 0.857 & 3194 & 227 \\
Average peer experience / tenure & -0.379 & 0.901 & 3155 & 227 \\
Permanent productivity ${ }^{a}$ & 0.502 & 0.893 & 3430 & 237 \\
Call quality $\left(y_{i t}^{q}\right)$ & 0.507 & 0.064 & 345 & 171 \\
Composite productivity $\left(y_{i t}^{\prime}\right)$ & 0.249 & 0.074 & 7489 & 355 \\
Grade 1 & 6.876 & 2.232 & 841 & 112 \\
Grade 2 & 6.404 & 2.294 & 850 & 112 \\
Grade 3 & 6.034 & 2.734 & 776 & 105 \\
Tenure in working weeks (in years) & 0.183 & 0.145 & 6451 & 303 \\
Tenure in fte weeks (in years) & 0.317 & 0.239 & 6451 & 303 \\
\hline \hline
\end{tabular}

$* p<\overline{\overline{0.10,{ }^{* *} p<0.05,{ }^{* * *} p<0.01 \text {. Descriptive statistics are based on the average for each individual }}}$ agent. Agents with one year of tenure at most are considered. Standard deviations in parenthesis. Permanent productivity is calculated from fixed effects $\theta_{i}$ which are obtained from a regression of average handling time $\left(y_{i t}\right)$ on individual fixed effects, and a full set of dummies for each level of tenure $d$ (see Equation (4). For the calculation of the variable composite productivity, see Section 4.3 Grades are given on 'knowledge of agent' (grade 1), 'agent understood question' (grade 2), 'solution of the problem' (grade 3 ). Grades are given on a scale from 1 (very bad) to 10 (very good). Tenure in working weeks is defined as the number of working weeks an agent worked. Tenure in fte weeks is defined as the number of fte working weeks an agent worked.

${ }^{a}$ based on the full data. 
Table 4: The effect of peers' experience on individual performance

\begin{tabular}{lcccc}
\hline \hline & $(1)$ & $(2)$ & $(3)$ & $(4)$ \\
\hline $\log ($ tenure) & $.0476^{* * *}$ & $.0487^{* * *}$ & $.0469^{* * *}$ & $.0449^{* * *}$ \\
Average team performance $t-1$ (std.) & $(.0028)$ & $\begin{array}{c}(.0037) \\
.0097^{* *}\end{array}$ & $(.0041)$ & $(.0033)$ \\
& & $(.0039)$ & & \\
Average team tenure $t-1$ (std.) & & & $.0109^{* * *}$ & \\
& & & $(.0040)$ & \\
Average peer experience / tenure (std.) & & & & $.0088^{*}$ \\
& & & & $(.0053)$ \\
Constant & $.3625^{* * *}$ & $.3613^{* * *}$ & $.3605^{* * *}$ & $.3604^{* * *}$ \\
& $(.0170)$ & $(.0173)$ & $(.0180)$ & $(.0170)$ \\
\hline Week fixed-effects & Yes & Yes & Yes & Yes \\
Control variables & Yes & Yes & Yes & Yes \\
\hline Observations & 3430 & 3194 & 3155 & 3430 \\
Number of agents & 237 & 227 & 227 & 237 \\
$\mathrm{R}^{2}$ & .3945 & .3734 & .3767 & .3991 \\
\hline
\end{tabular}

$* \overline{\overline{p<0.10,{ }^{* *} p<0.05,{ }^{* * *} p<0.01 \text {. Dependent variable: } y_{i t} \text {. Average team performance is defined }}}$ the performance average of peers within the team. Average team tenure is defined accordingly. Average peer experience is calculated as the sum over average team tenure in the past, normalised by the number of periods an agent has been working. All peer variables are weighted by joint hours between agent $i$ and other agents $j$ and standardised with a mean of 0 and a standard deviation of 1 . All regressions are estimated using observations with a maximum of one year of tenure. Control variables are previous employment, working hours, and gender. Standard errors are clustered at the agent level. 
Table 5: The effects of tenure on new hires

\begin{tabular}{lccc}
\hline \hline & All & Stayers & Leavers \\
& $(1)$ & $(2)$ & $(3)$ \\
\hline $\log ($ tenure $)$ & $.0444^{* * *}$ & $.0516^{* * *}$ & $.0385^{* * *}$ \\
& $(.0027)$ & $(.0040)$ & $(.0034)$ \\
Working hours & .0002 & -.0001 & .0005 \\
& $(.0004)$ & $(.0005)$ & $(.0004)$ \\
Gender $(1=$ male $)$ & .0015 & .0013 & .0031 \\
& $(.0085)$ & $(.0121)$ & $(.0106)$ \\
Constant & $.3685^{* * *}$ & $.4000^{* * *}$ & $.3468^{* * *}$ \\
& $(.0125)$ & $(.0205)$ & $(.0141)$ \\
\hline Week fixed-effects & Yes & Yes & Yes \\
\hline Observations & 6451 & 2177 & 4274 \\
Number of agents & 303 & 96 & 207 \\
$\mathrm{R}^{2}$ & .2916 & .3967 & .2610 \\
\hline \hline
\end{tabular}

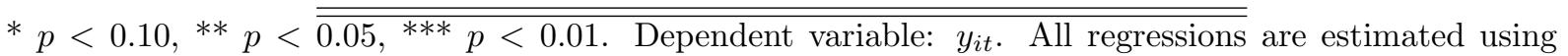
observations with a maximum of one year of tenure. Furthermore, only new hires are included. New hires are defined as agents who are observed from their first working week. Leavers (stayers) are defined as agents who do (not) drop out within our observation period. Standard errors are clustered at the agent level. Previous experience is included from these regressions because of missing variation in one of the regressions.

Table 6: Selection into teams

\begin{tabular}{lc}
\hline \hline & $(1)$ \\
\hline Average Permanent Productivity & -.2922 \\
& $(.1836)$ \\
Constant & $.2504^{* * *}$ \\
& $(.0365)$ \\
\hline Observations & 343 \\
Number of agents & 170 \\
$\mathrm{R}^{2}$ & 0.005 \\
\hline
\end{tabular}

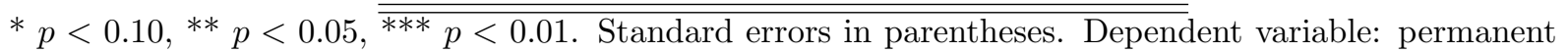
productivity of agent $i$ when switching from team $j$ to team $k, y_{i j}$. Average permanent productivity is the mean of permanent productivity of all agents in destination team $k$ to which an agent is switching to, $\bar{y}_{i k}$ (excluding the agent's own permanent productivity). Permanent productivity is calculated from fixed effects $\theta_{i j}$ which are obtained from a regression of average handling time $\left(y_{i t}\right)$ on individual fixed effects, and a full set of dummies for each level of tenure $d$ (see Equation 4). 
Table 7: The effect of tenure on quality

\begin{tabular}{lccccc}
\hline \hline Outcome & $\begin{array}{c}\log \left(y_{i t}^{q}\right) \\
(1)\end{array}$ & $\begin{array}{c}\log \left(y_{i t}^{\prime}\right) \\
(2)\end{array}$ & $\begin{array}{c}\text { Grade 1 } \\
(3)\end{array}$ & $\begin{array}{c}\text { Grade 2 } \\
(5)\end{array}$ & $\begin{array}{c}\text { Grade 3 } \\
(5)\end{array}$ \\
\hline $\log ($ tenure $)$ & $-.0193^{* * *}$ & $.0332^{* * *}$ & .0046 & -.0659 & .0236 \\
& $(.0031)$ & $(.0020)$ & $(.1473)$ & $(.1420)$ & $(.2035)$ \\
Previous employment & $-.0325^{* * *}$ & $.0326^{* * *}$ & .3549 & .3817 & .5665 \\
& $(.0125)$ & $(.0106)$ & $(.3977)$ & $(.2570)$ & $(.4293)$ \\
Working hours & $-.0013^{* * *}$ & .0001 & -.0081 & -.0020 & -.0021 \\
& $(.0004)$ & $(.0002)$ & $(.0127)$ & $(.0107)$ & $(.0135)$ \\
Gender $(1=$ male $)$ & .0027 & .0074 & .2920 & .2629 & .2355 \\
& $(.0084)$ & $(.0067)$ & $(.1874)$ & $(.1865)$ & $(.2642)$ \\
\hline Week fixed-effects & Yes & Yes & Yes & Yes & Yes \\
\hline Observations & 7133 & 7133 & 736 & 745 & 674 \\
Number of agents & 330 & 330 & 103 & 103 & 96 \\
$\mathrm{R}^{2}$ & .2765 & .2882 & .0507 & .1068 & .0507
\end{tabular}

$* p<0.10,{ }^{* *} p<0.05,{ }^{* * *} p<0.01$. All standard errors are clustered at the agent level. Call quality $y_{i t}^{q}$ is measured as $1 /$ (share of repeat calls*10). The composite productivity measure $y_{i t}^{\prime}$ is defined as $y_{i t}^{\prime}=a h t_{i t} *(1-$ share of repeat calls). Grades are given on 'knowledge of agent' (Grade 1), 'agent understood question' (Grade 2), and 'solution of the problem' (Grade 3). Grades are given on a scale of 1 (very bad) to 10 (very good). 
Table 8: Determinants of performance using different tenure definitions

\begin{tabular}{lccc}
\hline \hline & $(1)$ & $(2)$ & $(3)$ \\
\hline $\log$ (tenure in calendar weeks) & $.0444^{* * *}$ & & \\
& $(.0026)$ & & \\
$\log$ (tenure in working weeks) & & $.0459^{* * *}$ & \\
& & $(.0026)$ & \\
$\log$ (tenure in fte weeks) & & & $.0409^{* * *}$ \\
& & & $(.0025)$ \\
Previous employment & $.0573^{*}$ & .0496 & .0491 \\
& $(.0315)$ & $(.0350)$ & $(.0340)$ \\
Working hours & .0002 & .0001 & $-.0008^{* *}$ \\
& $(.0004)$ & $(.0004)$ & $(.0004)$ \\
Gender $(1=$ male) & .0017 & .0013 & .0016 \\
& $(.0085)$ & $(.0084)$ & $(.0084)$ \\
Constant & $.3677^{* * *}$ & $.3745^{* * *}$ & $.4140^{* * *}$ \\
& $(.0125)$ & $(.0124)$ & $(.0131)$ \\
\hline Week fixed-effects & Yes & Yes & Yes \\
\hline Observations & 6451 & 6451 & 6451 \\
Number of agents & 303 & 303 & 303 \\
$\mathrm{R}^{2}$ & .2953 & .3043 & .2933 \\
\hline \hline
\end{tabular}

$* p<0.10, * \bar{*} p<0.05,{ }^{* * *} p<0.01$. Dependent variable: $y_{i t}$. All standard errors are clustered at the agent level. All regressions are estimated using observations with a maximum of one year of tenure. 'Tenure in working weeks' is defined as the number of working weeks an agent worked. 'Tenure in fte weeks' is defined as the number of fte weeks an agent worked. All regressions include new hires only which are defined as agents who can be observed from their first working week. 